\title{
The Big Five Factors of Personality and Its Relation to Emotional Intelligence among Leaders of Educational Institutions in the State of Kuwait
}

\author{
Abdul Majid Al-Nasser, Marzouq Al-Enezy \\ Faculty of Human and Social Sciences, University of Tunis, Tunis, Tunisia \\ Email:mar.enezy@hotmail.com
}

How to cite this paper: Al-Nasser, A. M., \& Al-Enezy, M. (2018). The Big Five Factors of Personality and Its Relation to Emotional Intelligence among Leaders of Educational Institutions in the State of Kuwait. Psychology, 9, 1680-1694.

https://doi.org/10.4236/psych.2018.97099

Received: May 7, 2018

Accepted: July 7, 2018

Published: July 10, 2018

Copyright (c) 2018 by authors and Scientific Research Publishing Inc. This work is licensed under the Creative Commons Attribution International License (CC BY 4.0).

http://creativecommons.org/licenses/by/4.0/

(c) (i) Open Access

\begin{abstract}
The goal of thesis is to know the relation between the Big Five Factors of Personality and the Emotional Intelligence among Leaders of Educational Institutions in the State of Kuwait. The researcher used Descriptive Approach using following study tools: Big Five Factors of Personality Scale (Researcher translation)-Emotional Intelligence Scale as of Ability (Prepared by Othman AlKhodor). The sample of the study was (93) detailed as follow: (36 male) and (57 female) educational leaders of Kuwait Secondary Schools which belongs to Ministry of Education, Mubarak Al-Kabeer Educational Area. Researcher used SPSS Program (Statistical Pack of Social Science) at data entry and the statistical processing. Also used the following statistical methods: Arithmetic Averages, Standard Deviation, Pearson correlation coefficient, (t-test) Test of the differences between the averages, analysis of variance and Cronbach's alpha formula for persistence. The results were revealed as follows: 1) Existence of positive relation between four of the Big Five Factors of Personality and was reverse with the empirical factor. 2) There was no existence of a relation between degrees of the Big Five Factors and the degrees of the Emotional Intelligence as ability. 3) There was no existence of a relation between total degrees of the Emotional Intelligence scale and degrees of Emotional Intelligence as ability. 4) There were no differences between male and female in the averages of Emotional Intelligence as ability, in the averages of Emotional Intelligence and in the averages of the Big Five Factors of Personality.
\end{abstract}

\section{Keywords}

Personality, Emotional Intelligence, Leadership 


\section{Introduction}

Thesis contain the following: Abstract, Introduction, Study Problem, Study Goals, Study Terms, Study Procedures and Methodology, Theoretical Framework: Personality Big Five Factors \& Emotional Intelligence, Previous Studies \& Discussion, Study Methodology, Results, Recommendations, Suggestions \& References.

The Big Five Factors of Personality are considered an inclusive theory for describing the personality treats through big five factors represented in extraversion, agreeableness, conscientiousness, neuroticism, openness which experts can stop on positive personality treats of an individual. They choose the suitable individual to put in the right place of a position. The Emotional intelligence is considered as the ability of an individual to understand his emotions with work colleagues and outside work with family and society, knowing those emotions and stopping at them through realizing their feelings and the ability for discrimination and differentiation between them in addition for the ability to control dealing with them positively.

The Educational Leaders considered a main corner in society development for their effective role based on developing educational institutions, those institutions are men manufacturer and their outputs is the base of future and its leaders. Therefore there is a necessary need for a leading educational institution which graduate a new generation aware of his abilities and potentials, to be an effective member and productive at his home with family, at work with colleagues, in society with relatives and friends, therefore whenever outputs of educational institutions were good then the whole society will be good in general.

The Researcher used Theories of the Following Personality: The Theory of Psychoanalysis-Sigmund Freud, Gorden Allport, Carl Rogers, Eysenck. The following emotional intelligence theories were used Ability mode \& Mixed model.

\section{Importance of Study}

The current study derived its importance from the importance role of the Personality Big Five Factors in building a leading personality. Which makes big importance in the educational institutions therefore in the whole society. It is based on building, progress, growth, development and political, economical, social and educational development for any society. Since school is the factory of coming generation and is responsible for its outputs. This phenomena gets its importance out of being educational leaders represent main tributary for society. Also for the need of society for efficient qualified individuals and able to occupy high school managers in the State of Kuwait. To be a tool for a best change, build and progress in modern societies.

The Researcher used Descriptive Approach using following study tools: Big Five Factors of Personality Scale (Researcher translation)-Emotional Intelligence 
Scale as of Ability (Prepared by Othman AlKhodor). The sample of the study was (93) detailed as follow: (36 male) and (57 female) educational leaders of Kuwait Secondary Schools which belongs to Ministry of Education, Mubarak Al-Kabeer Educational Area. Researcher used SPSS Program (Statistical Pack of Social Science).

\section{Study Problem}

The problem of the current study was determined through the researcher's feelings of hardness for controlling feelings among some educational leaders in the educational institutions at the public education of Kuwait. Some of the leaders were not able to understand or know the emotions of the employees and the students at school. They were unable to distinguish between those emotions in addition for inability to deal with it positively. Accordingly there is low in emotional intelligence among some educational leaders and there is no interest within specialized sides when choosing those educational leaders of their personality treats.

This feeling was growing in the researcher's throughout living with that in the researcher's educational work, in addition to the four children researcher has and those children study in the educational institutions of the public education, furthermore the researcher has seen previous studies in the study field The Big Five Factors of Personality and its relation with Emotional Intelligence among Leaders of Educational Institutions in the State of Kuwait.

Throughout mentioned above, the researcher found that this phenomenon is existing in The State of Kuwait and has its effect on the teamwork of educationalists, administrative and students in the educational institutions which negatively effects society of Kuwait, therefore there is a need to make this study to know the big five factors of personality and its relation with emotional intelligence among Leaders of Educational Institutions in the State of Kuwait. And through the study problems, the following questions comes up:

1) What is the relation between Personality big five factors and the emotional intelligence scale and its sub-dimensions?

2) What is the relation between Personality big five factors and the emotional intelligence scale as ability?

3) What is the relation between the emotional intelligence scale and its sub-dimensions and the emotional intelligence scale as ability?

4) What are the differences between averages of male and female leaders in the study variables: Emotional Intelligence scale and its sub-dimensions and the Emotional Intelligence scale as ability and between the Personality Big Five Factors scale?

\section{Study Assignments}

1) There is no analytical functional relation between TPBFF and the whole Emotional Intelligence scale and its sub-dimensions. 
2) There is no analytical functional relation between TPBFF and the Emotional Intelligence scale as an ability.

3) There is no analytical functional relation between Emotional Intelligence scale and its sub-dimensions and Emotional Intelligence scale as an ability.

4) There are no analytical functional differences between averages of males and females of leaders in the study variables for Emotional Intelligence scale and its sub-dimensions and the Emotional Intelligence scale as ability and The Personality Big Five Factors scale.

\section{Study Goals}

The current study aimed for an attempt to know the relation in between Personality Big Five Factors and the Emotional Intelligence among Kuwait Educational Leaders.

\section{Study Terms}

Personality Big Five Factors: McCrae \$ John defined PBFF as a hormone order which include five main factors: Extraversion, Neuroticism, Conscientiousness, Agreeableness and Openness to Experience (McCrae \& John, 1992, 175).

Emotional Intelligence: defined by (Goleman, 1995): The ability to understand emotions, know it, discriminate them and ability to control it and deal with it positively (Fai: Al-Shehry, 2010: p. 20).

Leadership: defined by (Al-Ajmi, 2010): The ability to coordinate different groups of people at work and deal with different tasks in an unstable, changeable environment. Leaders to submit direction and vision that can be achieved completely in the institution. Leadership derives its power from the valuables and principles the institution based on, the leadership is directed for future which makes it the important factor in the success of the institutions on the long term (Al-Ajmi, 2010, 194).

Educational Leadership: defined by (Abawy, 2010): Practices, management and educational activities in the educational and university institutions that an educational leader fulfills whether a manager, university dean or head of a department throw his direct or indirect interaction with teachers, students and other staff in the intend of influencing them and building human relation with them and making them cooperate and feel they belong to this educational institution or university they work with and contribute achieving its goals (Abbas, 1999: p. 31).

Educational Leader: defined by (Abawy, 2010): The Person who has knowledge and ability to stimulate motivation and achieve success among all students based on their work on integrity, justice, career ethics accordingly he would know students needs and abilities, consider individual differences, their tendencies and preparations, continuously motivate them for good performance, deals with them as a facilitator able to participate and organize and spread proper ethics in 
between them with a spirit of love and cooperation (Abowy, 2010: p. 76).

\section{Study Limits: The Study Limited by the Following}

- Human limitations: The study confined Educational Institutions leaders category who are High School Managers for both male and female in the Ministry of Education, Public Education sector.

- Spatially Limits: The study applied in public schools of Ministry of Education.

- Time Limits: Current study applied on 2017.

\section{Study Procedures and Methodology: Researcher Will Continue the Descriptive Methodology}

Study Society: Educational leaders (male/female) in public education. Study Sample: 93 leader of educational institutions.

Study Tools:

1) Personality Big Five Factors, (prepared by researcher).

2) Emotional Intelligence as ability, (prepared by Othman).

3) Emotional Intelligence, (prepared by researcher) (Al-Enezy, 2015).

\section{Theoretically}

Researcher deals with theoretically side in the next lines, which includes Personality Big Five Factors, Emotional Intelligence and Educational Leadership as follows:

\subsection{Personality Big Five Factors}

Personality is hard science to collect its parts. Personality Scientists has collected parts of this science, through indicating many of personality traits, except that personality specialists found the number of personality traits larger than thousands therefore they tried to restrict the personality factors in big factors. Although scientists agreed to eliminate big factors but they were different in its number of those factors.

\section{Applied Personality Big Five Factors:}

The sample of PBFF is a result of many decades of research and analysis for the factors on the personality traits, as seen by (Taylor \& McDonald, 1999) Galton was the first one closer to the sample, followed in trying by Albert \& Audit (1963), Chrystal (1961) and Norman (1963).

The sample of PBFF can be understood as a theory describes personality traits and classifies it. It includes five main independent dimensions were derived through results of certified researches. The sample of PBFF was noticed by number of psychological scientists who were interested of studying personality. Works of (Costa \& McCrae, 1992) considered interest worthy. They designed the first objective tool that aims to measure the main personality big factors through a group of items that was extracted by factor analysis of a container of items de- 
rived from many personality intelligences.

Also (Taylor \& McDonald, 1999) sees that the list did not prove that it does not have good psychometric characteristics only but proved that it accommodate many included thoughts in the other personality lists such as personality pattern indicator for Mayors-Briges (1987), and the sixteen personality factors list for Raymond Catle, in addition to the connection with of Ayzonic personality intelligence which is considered to be the most popular personality intelligence, further more that it has been succeeded in the research of the personality and its relation with number of important variables such as: creativity, thinking, motivation and decision making (Abdulmune'em, 2007: pp. 11-12).

McCrae \& John defined Personality Big Five Factors as: pyramidal arrangement of PBFF which includes five basic factors which are: Extraversion, Neuroticism, Conscientiousness, Agreeableness and Openness to Experience (McCrae \& John, 1992, 175).

\section{For current study the factors based on are as follows:}

Boshra Ismail defined Extraversion: It is a couple pole dimension extends from extrusion to inclusion, and it is the axis that organizes behavior phenomenon from where it displays of vibrate phenomenon between dash and stop, and what displays of trendiness within a person to attach to values derived from the outside world or values derived from the inner world (Ismail, 2007: p. 217).

Taha defined Agreeableness in Encyclopedia of psychology and psychoanalysis: specially used in taking opinions or voting on decisions or on individual situations, reports and selections when taking into consideration in all that agreement with others and harmony with others opinions until it becomes acceptable from their side. Here he refers to the urgent desire individually to agree with others and not to take an attitude away from them but to take the same situation they take so they accept him. This concept used a lot in psychological scales. The concept meant a selection person makes for a responses that might others choose or prefer to choose or satisfies them and makes him been accepted (Taha, Qandeel, Mohammad, \& Mostafa, 2009: p. 1191).

Abdulmene'em defined Conscientiousness: Includes a number of traits such as Efficiency, Order, feel of obligatory, assiduity in accomplishment, personal discipline, visibility and who gets high mark in this factor described as responsible and has strong determination, characterization, ability of concentration in work, desire to accomplish achievements (Abdulmune'em, 2007: p. 13).

AbdulKhaleq defined Neuroticism: It is a basic dimension of a personality and it counters emotional balance. It signs for readiness of psychological abnormality affliction which is neurosis. So that real Neurosis appears there must be - next to the high degree of neurosis_ high degree of environmental external or internal pressure, hardship or stress (Abdulkhaleq, 1996: p. 72).

Al-Husaini defined Openness to Experience: This factor measures search for new experts, Realize expert from its source, desire for discovery, afford ambiguity and the higher factor of those has wide tendency, exploration, innovation, 
authenticity, imagination and untraditional but the lower is traditional, non analytical and has narrow tendencies (Al-Husaini, 2004: p. 8).

Personal Theories: Theory of psychoanalysis: Freud considered the first who submitted explanation for human soul. His view that integrated personality involving three aspects: biological side represented by (him/the other), psychological side represented by (me/ego) who is the center of higher mental processes and will. And social side represented by (superego) and those sides are in an ongoing conflict. The function of the ego is to reconcile the demands of the other (him) with the demands of the external reality and the demands of conscience. If the ego succeeds in reconciling these demands, the personality moves towards integration and balance. If it fails in its job, then the poor coordination and the individual's progress in the path of deviation and crime (Hall \& Lindsey, 1969: p. 53). Theory of personality: Allport in his theory mentions that traits characteristics are integrated and they are the natural unit to describe personality. And the most important principles underlying his theory of personality were: Public-Motivation-Functional Independence-Ego or Self (Khory, 1996: p. 43).

Carl Rogers Theory: Rogers' character building is based on the individual's experience, perception and evaluation. And that the individual is his concept of himself through his continuous interaction with his environment and also through the evaluation of others. The idea of self is the basis of Rogers' theory. Rogers' focus is now and here. It is believed that man himself is more than understands himself. Both Allport \& Rogers agreed that the self was the basis for their theories (Khory, 1996: pp. 45-46). The road is still too early to reach Eysenck: H.J. Eysenck mentions the theory of Hans's theory of personality. But he sees that there are two basic styles of characters, one Diastolic as if the other has grabbed the stick from the middle Introverted. These two characteristics characterize the behavior of the individual. Eysenk said that the personality is based on two diastolic and introverted patterns and between them point zero and that the individual finds a place where is not clear features either in the first party as diastolic or the other side as an introverted or between them (Jaber, 1986: p. 328).

\subsection{Emotional Intelligence}

Emotional Intelligence concept: (Goleman) mentioned that ability of a person to manage his thoughts, emotions and behavior to a degree makes him feel more happy, success and satisfied life (Fai: Ismail, 2007: p. 110).

(Mayer \& Salovy, 1997) Emotional Intelligence is the ability to realize emotions, evaluate them, express them, ability to generate emotions, emotional knowledge and ability to organize emotions to enhance emotional and mental growth (Fai: Faraj \& Abdulmajeed, 2010: p. 614).

\section{Samples of Emotional Intelligence:}

Emotional Intelligence can be seen through two big directions:

- Ability Model: Except Salovy after that submitted with Mayer a model of 
Emotional Intel identifying emotions, using emotions to simplify thinking job, understand emotions and manage emotions. This sample became different not only with ligence called it Ability Sample including four components: its previous one but with Goleman's sample too. Because of its concentration on cognitive abilities about emotional and personal aspects (Fay: Al-Behairy, 2007: p. 590). He also views emotional intelligence as a group of separate abilities that form in between it emotional intelligence. Some of those who follow that direction are: Mayer, Salovy, Carsco (Mohammad, 2007: p. 485).

- Mixed Model: Bar-Oown suggested Emotional Factors (EQ) mentioning that it is contained of five components inside a person, between a person and other, ability to adapt, managing pressure and the general mood. This sample is called Mixed Sample (Fay: Al-Behairy, 2007: p. 59), and he who sees Emotional Intelligence describing it an outcome for a very big group of skills and characteristics, the emotional intelligence is renewed for a person according to the skills ones owns, he is able to do, those who follow that direction: Bar-Oown, Goleman (Mohammad, 2007: p. 485).

\section{Emotional Intelligence Dimensions:}

Researcher definition for Emotional Intelligence Dimensions: As follows:

- Self Awareness: Understanding a person oneself, realizing his feelings, his ability to control and manage emotions, his ability to stop by his own strength and defect points where to be able for compatibility and ability to dispose negative feelings, his ability and realization to work on achieving goals.

- Self Regulation: Ability of a person to control his feelings and his negative behavior, his manners responsibility in different fields of life, his ability for compatibility and adaptation with society and environment, flexibility in accepting others ideas and the way dealing with.

- Motivation: The power that moves a person either inner or outer one, in addition to perseverance, assertion with existence of hope to quest and do the best potential efforts a person may have to achieve a certain goal.

- Empathy: Ability to understand and realize others feelings from voice tone or facial expressions or gestures without reliance or need for explanation of words or sentences.

- Social Skills: Person's ability to manage changing operation through what he owns of social skills, in addition to the skill of dealing with others, simulation, imitation, role exchange, and that won't be except with understanding their feelings and caring.

\subsection{Educational Leadership}

Leadership considered social psychological phenomena based on exchangeable reliability relationship between leader and other group members that is managed, results of leaders influence on group and the desire of a group for docility to satisfy needs. There is no way for leadership without liabilities, and leader's prominence 
in a group and his survival is mortgaged to availability of a goal the group are seeking to achieve. It is the important meeting point between a leader and a group, activity field and nature of formation (Kana'an, 2009: p. 97).

Importance of Educational Leadership at Educational Institutions:

The importance of educational leadership clears in the move of effective spirit where it derives its dynamism and effectiveness from the efficient leader, while works under his power, responsibility and directions all effectiveness towards work valuables and educational institutions functions (Abawy, 2010: p. 79).

Basic Skills Required for Educational Leadership:

Self Skills: It contains some traits, mental abilities, innovation and self control.

Normal Technical Skills: It is specialized knowledge in one branch of science and efficiency in using this efficiency in achieving required goal effectively, this skills obtained through knowing, experience and training.

Social Humanitarian Skills: It means Leader's ability to deal with his subordinates, coordinate their efforts in creating teamwork among them.

Cognitive Pictorial Skills: It is leader's ability to view coordination he leads, understands the interconnection between its parts, his ability to imagine and understands relations of an employee in an institution, institutions relations as whole with the society that he works with (Al-Ajmy, 2010: pp. 69-70).

\section{Previous Studies}

First: Studies dealt with a variable of TPBFF and its relation with other variables:

Study (Al-Shara'a, 2012): (Al-Shara'a, 2012) made a study aimed to know the ability of predictability of TPBFF in the irrational thoughts, the sample of the study were (250) students (male/female) in the fourth stage of the University of Mo'atah, Most important results of the study: The most common factor between students was the ability (Excessive, Openness, Approval), and neuroticism and openness are the most personality factors ability of predictability of the irrational thoughts.

Study (Shuwaikh, 2012): (Shuwaikh, 2012) made a study aimed to know the relation between TPBFF and Healthy Manner Patterns among university students, The study tools included Form of first data form, List of Personality Big Five Factors, Health Manner Intelligence, The sample included (400) student (male/female) in the University of Southern Vale (173 Males/227 Females), The most important study results: existence of a relation between TPBFF and Heath Manners Patterns, and the importance of neuroticism in compare of other factors in the role of predicting of all health manners patterns.

1) Studies dealt with Emotional Intelligence variable and its relation with some other variables:

Study (Rashed \& Al-Husaini, 2012): (Rashed \& Al-Husaini, 2012) made a study aimed to prepare guidance program to improve Emotional Intelligence in relieve tension of future among sample of study, the study sample was (31) 
teacher of private education, the researcher used Emotional Intelligence Scale and Future Anxiety Scale, most important results: No analytical differences between the average of private education teachers degrees in both scales dimensional and tracking one of Future Anxiety Scale.

Study (Ghunaim, Anwar, \& Zaki, 2012): (Ghunaim, Anwar \& Zaki, 2012) made a study aimed to know the extent of differentiation or non differentiation of Emotional Intelligence out of all determinants of moral manners, The study sample included (270) student (male/female) aged between (13-14) in the second stage of middle schools of Qalyoubia Governorate in Egypt, Researchers used Emotional Intelligence scale, Manners Scale, Issues Elimination scale, Moral Motivation scale and The Power of I scale to measure moral personality, The most important study results: no differentiation of the Moral Manners dimensions and the dimensions of Emotional Intelligence.

2) Studies dealt with Variable of TPBFF and its relation with the Emotional Intelligence variable:

Study (AbdulQawy, 2010): (AbdulQawy, 2010) made a study aimed to know the nature of relations between TPBFF and Emotional Intelligence among sample of University Tabook female students (400) student, The stability of the scale sub-factors was high either from inner consistency or repetition, the study also used emotional intelligence scale prepared by (Habbab Othamn), and verification was done of stability and truth of the tools used, the researcher codified the scale to suit the Saudi environment .The most important study results: existence of connection relation of analytical function between TPBFF and Emotional Intelligence, but there was no functional relation between neuroticism and emotional intelligence, the explanation of results done at theoretical framework.

\section{3) Previous Studies discussion:}

After displaying previous studies that dealt with TPBFF and its relation with Emotional Intelligence the researcher able to discuss those studies from different fields and sides to give a perception of what been dealt with and sowed those studies out of the results, and to benefit in stating goals, tools, sample and results to know what could that contribute scientifically and theoretically for the current study.

The researcher quoted some previous studies and were arranged as follows: (studies dealt with TPBFF and its relation with some other psychological variables-Studies dealt with Emotional Intelligence and its relation with other psychological variables-studies dealt with TPBFF and its relation with Emotional Intelligence). The goals of those studies were different according to the study problem, also it was different in the sample of the study, tools and results, and the current study came different than all other previous studies of goal, problem, sample and tools, because of concentrating on the emotional intelligence as ability of knowledge to become unilateral of other studies that adopted mixed sample, and the importance of its problem came out the importance of the sample that included the educational leaders for their important role in the 
educational institutions, in addition to the tools which is TPBFF which is translated and coded by researcher, Emotional Intelligence scale as knowledge ability which is rarely applied in the Arabian Gulf Region.

\section{Methodology and Procedures of Study}

Current chapter deals with the procedures followed in the study such as: description of procedures study, society, study sample, study tools, steps researcher followed to assure honesty and stability of study tools, statistical techniques used by researcher to get results of current study.

1) Study Methodology: in this study researcher relied on comparative engagement descriptive methodology.

2) Study Society: it was (115) educational leader in the public secondary schools at Mobarak Al-Kabeer educational area.

3) Study Sample: been intentionally selected, the total size of the sample was (93) educational leader, male (36), female (57), following will display study assignments result.

\section{Study Scales}

\section{1) The Personality Big Five Factors scale:}

Researcher relied in the honesty and stability for the personality big five factors prepared by: John, Donahue \& Kentle, 1991 and translated by researcher, on the study done by Mr. Marzouq Al-Enezy (2011) that was made for Kuwaiti Environment.

\section{2) Emotional Intelligence Ability scale:}

Researcher relied in the honesty and stability of Emotional Intelligence Scale as ability done by: Othman Al-Khodor, on the study made by Dr. Othman Al-Khodor (2006) which was made about Kuwaiti Environment.

\section{3) Emotional Intelligence scale:}

Researcher relied in the honesty and stability on the research of Mr. Marzouq Al-Enezy that was done on Kuwaiti Environment under title of: Emotional Intelligence among Teachers of Kuwait, published at Educational Science Journal, special issue about the conference of psychological guidance section, under title: (role of psychological guidance science in renewing society), 27-28 May 2015, researcher displays steps of preparing emotional intelligence scale, which came as follows.

\section{Statistical Methods}

Researcher used statistical SPSS program for social science at entering data and statistically processing them and used the following statistical methods: (arithmetical average-normative deviation-Pearson connection factor-(t-test) differences indication test-contrast analysis-Cronbakh's Alpha stability equation).

\section{Study Results and Discussion}

1) First Impose: there is no relation of an statistical indication between 
personality big five factors and between the whole emotional intelligence scale and its sub-dimensions.

Pearson Connection Factor used to calculate the connecting relation between emotional intelligence and its sub-factors and between the big five factors of personality as per following Table 1 :

Results of Table 1 shows difference in the direction and indicators of connection between Personality Big Five Factors and Emotional Intelligence scale and its dimensions. Turns out existence of indicator for the positive direction in the relation between four of the Big Five Factors of Personality and the dimensions of Emotional Intelligence scale. While the relation was reverse with the Neuroticism factor, leadership a trait that comes with Agreeableness which is connected in a relation with the Emotional Intelligence in the result of the current study. The current result returns to the concept of Neuroticism which meets emotional balance. It indicates the readiness to be infected with psychological disorder (Neuroticism). This result indicates that the first impose was not achieved.

2) Second Impose: there is no relation of an statistical indication between personality big five factors and between emotional intelligence as ability.

Pearson Connection Factor used to calculate the connecting relation between Emotional Intelligence scale as ability and Personality Big Five Factors according to displayed Table 2:

Results of Table 2 shows that there is no functional statistical relation between the Big Five Factors (Extraversion, Agreeableness, Conscientiousness, Neuroticism and openness) and the degrees of Emotional Intelligence as ability. This result indicates the achievement of the second impose.

3) Third Impose: there is no functional statistical relation between Emotional Intelligence, its sub-dimensions and Emotional Intelligence scale as ability.

Pearson Connection Factor used to calculate the connecting relation between Emotional Intelligence as ability and between Emotional Intelligence scale and its sub-dimensions according to the Table 3 displayed below:

Results of Table 3 shows that there is no functional statistical relation between the total Scale of Emotional Intelligence and Self-awareness dimension,

Table 1. Calculation of connection factor between Personality Big Five Factors and Emotional Intelligence and its factors.

\begin{tabular}{ccccccc}
\hline Dimensions & Self-awareness & Self-organization & Motivation & Sympathy & Social-skills & $\begin{array}{c}\text { Total Scale } \\
\text { Em.In. }\end{array}$ \\
\hline Extraversion & 0.102 & $0.320^{* *}$ & $0.223^{*}$ & $0.234^{*}$ & $0.181^{*}$ & $0.282^{* *}$ \\
Agreeableness & 0.001 & $0.270^{* *}$ & -0.001 & 0.084 & $0.274^{* *}$ & 0.167 \\
Conscientiousness & 0.125 & 0.112 & 00.022 & 0.148 & 0.153 & 0.142 \\
Neuroticism & $0.175^{*}$ & 0.023 & $-0.211^{*}$ & -0.121 & -0.062 & -0.071 \\
Openness & $0.172^{*}$ & $0.198^{*}$ & $0.206^{*}$ & $0.177^{*}$ & 0.073 & $0.217^{*}$ \\
\hline
\end{tabular}

${ }^{\star}$ Function level number $0.05 ;{ }^{* *}$ Function level number 0.01 . 
Table 2. Calculation of connection factor between Personality Big Five Factors and Emotional Intelligence as ability.

\begin{tabular}{cc}
\hline Dimensions & Emotional Intelligence scale as ability \\
\hline Extraversion & -0.080 \\
Agreeableness & -0.059 \\
Conscientiousness & -0.117 \\
Neuroticism & -0.096 \\
Openness & -0.099 \\
\hline
\end{tabular}

${ }^{\star}$ Function level number 0.05 ; ${ }^{*}$ Function level number 0.01 .

Table 3. Calculation of connection factor between Emotional Intelligence Scale and Emotional Intelligence as ability.

\begin{tabular}{cc}
\hline Dimensions & Emotional Intelligence scale as ability \\
Self-awareness & -0.118 \\
Self-organization & -0.077 \\
Motivation & -0.009 \\
Sympathy & -0.132 \\
Social Skills & -0.019 \\
Total Scale & -0.078 \\
\hline
\end{tabular}

Motivation, Sympathy and Social Skills to results of Emotional Intelligence as ability. Recent result did not match with results of previous studies. That indicates the achievement of third impose.

4) Forth Impose: there is no functional statistical differences between Averages of Male and Female of leaders in the variables of the study Emotional Intelligence scale, its sub-dimensions and Emotional Intelligence scale as ability and Personality Big Five Factors scale.

Used $\mathrm{T}$ Test to differentiate the differences of groups in the Emotional Intelligence dimensions and its total degree which return to the sex as per the following displayed Table 4 below:

Results of Table 4 shows that there are no differences between Male and Female in the skills of Emotional Intelligence: Self-Awareness, Self-Organization, Motivation, Sympathy and Social Skills. There is no differences in the Emotional Intelligence as ability. There is no differences even in the Personality Big Five Factors: Extraversion, Agreeableness, Conscientiousness, Neuroticism and Openness.

Probably the recent result returns to the similarity of socialization characteristics for both male and female in Kuwait that they got from their parents on their childhood. As they were equal in their acquired rights and their duties. And to the social equality they get from the administration that is responsible for their jobs in Kuwait which is (Civil Service Commission), they get equal financial and moral facilities, they get training courses and educational lectures, which 
Table 4. Calculation of second test of differences between both sexes in the study variables (36 male - 57 female).

\begin{tabular}{ccccccc}
\hline Dimensions & $\begin{array}{c}\text { Average } \\
\text { male }\end{array}$ & $\begin{array}{c}\text { Average } \\
\text { female }\end{array}$ & $\begin{array}{c}\text { Standard } \\
\text { Deviation } \\
\text { male }\end{array}$ & $\begin{array}{c}\text { Standard } \\
\text { Deviation } \\
\text { Female }\end{array}$ & T value & Significance \\
\hline $\begin{array}{c}\text { Emotional } \\
\text { Intelligence Ability }\end{array}$ & 38.72 & 37.33 & 4.978 & 5.789 & 1.188 & 0.238 \\
Self Awareness & 18.31 & 19.16 & 2.974 & 3.104 & -1.311 & 0.193 \\
Self Organization & 17.86 & 18.02 & 3.314 & 3.578 & -.211 & 0.833 \\
Motivation & 18.89 & 20.39 & 4.628 & 4.419 & -1.563 & 0.122 \\
Sympathy & 20.25 & 20.51 & 2.677 & 3.670 & -0.366 & 0.715 \\
Social Skills & 19.97 & 18.91 & 3.946 & 4.206 & 1.212 & 0.229 \\
Emotional & 95.28 & 96.98 & 11.783 & 15.334 & -0.569 & 0.571 \\
Intelligence & 30.00 & 28.77 & 3.617 & 3.616 & 1.595 & 0.114 \\
Extraversion & 30.44 & 29.26 & 3.783 & 3.097 & 1.643 & 0.104 \\
Agreeableness & 31.53 & 30.61 & 3.393 & 3.483 & 1.244 & 0.217 \\
Conscientiousness & 26.19 & 24.68 & 4.174 & 3.418 & 1.903 & 0.060 \\
Neuroticism & 34.67 & 35.42 & 6.178 & 6.333 & -0.565 & 0.574 \\
Openness & & & & & & \\
\hline
\end{tabular}

resulted a positive effect in formation their characteristics and skills growth and that result indicates achievement of the fourth impose.

\section{Recommendations \& Suggestions}

1) Ministry of Education to adopt training programs for the goal of rising up level of educational leaders in the Emotional Intelligence.

2) Ministry of Education to adopt training programs for the goal of facing sharpness of Neuroticism in the Personality of an educational leader.

3) Extraversion \& Neuroticism Factors and their relation with the Functional Acceptance among Educational Leaders.

4) Effectiveness of and training program based on skills of Emotional Intelligence to limit increasing of Neuroticism factor among educational Leaders.

\section{References}

Abawy, Z. M. (2010). The Role of Educational Leadership in Making Administrative Decisions. Jordan: Dar El Shorouk for Publishing \& Distribution.

Abbas, M. A. (1999). University Educational Leadership for the Deans of the Faculties and the Heads of the Scientific Departments as Seen by the University of Baghdad Teaching and Its Relations with Morals. Ph.D. Thesis, Ibn Roshd: Baghdad University.

Abdulkhaleq, A. M. (1996). Personality Scale. Authoring, Arabization and Publishing Committee, Scientific Publishing Council, Kuwait: Kuwait University Publications.

Abdulmune'em, A. M. (2007). The Big Five Factors of Personality and Its Relation to Methods of Academic Thinking and Achievement in the Light of Motivation for Achievement. Cairo: Cairo University.

AbdulQawy, R. A. A. (2010). The Five Big Factors of Personality and Its Relation to Emo- 
tional Intelligence among Female Students of Tabouk University (pp. 35-81). Algeria: Psychological Studies-Al-Basira Center for Research, Consultancy and Educational Services.

Al-Ajmy, M. H. (2010). Recent Trends in Administrative Leadership and Human Development. Jordan: Dar Al-Maseera Publishing.

Al-Behairy, M. R. (2007). Developing Emotional Intelligence to Reduce Sharpness of Some Problems among Sample of Behavior Troubled Children, Regional Conference of the Association of Egyptian Psychologists, 18-20 Nov 2007. Psychological Studies, 17, 585-641.

Al-Enezy, M. A. (2011). Character Traits and Their Relation to Decision Making among Administrative Leaders in State of Kuwait. Master Thesis, Bahrain: Psychological Counseling Section, College of Education, Gulf University.

Al-Enezy, M. A. (2015). Emotional Intelligence among Teachers in State of Kuwait. Journal of Educational Sciences.

Al-Husaini, H. H. (2004). Personality Five Big Factors-List of Qualities-Scale. Cairo: Anglo Library.

Al-Khodor, O. H. (2006). Designing Arabian Scale for Emotional Intelligence and Verifying Its Psychometric Characteristics and Its Connections, Egypt. Psychological Studies Journal, 16, 259-289.

Al-Shara'a, H. S. (2012). Predictability of the Five Big Factors in Personality with Irrational Thoughts. Journal of Educational Psychological Sciences-Bahrain, 13, 245-272.

Al-Shehry, W. M. (2010). Marital Compatibility and Its Relationship to Some Personality Traits among Sample of Married Teachers in Jeddah Province. Master Thesis, Department of Psychology, Education College, Umm Al Qura University.

Faraj, S., \& Abdulmajeed, N. M. (2010). Emotional Intelligence and Its Relation to the Five Big Factors of Personality. Psychological Studies, 20, 605-644.

Ghunaim, M. A. I., Anwar, H. M., \& Zaki, H. M. (2012). Emotional Intelligence and Moral Behavior: Factors Study. Journal of Faculty of Education, 23, 223-263.

Hall, C. S., \& Lindsy, G. (1969). Personality Theories. Qiro: Arab Thought House.

Ismail, B. (2007). Emotional Intelligence and Its Relation with Leading Pattern and Techniques of Facing Pressures among Sample of Management Leaders. Education College Journal, 159, 135.

Jaber, A. (1986). Personality Theories-Construction Dynamics Growth Research Methods Calendar. Qiro: Arab Renaissance House.

Kana'an, N. S. (2009). Administrative Leadership. Jordan: Dar Al-Thaqafa for Publishing and Distribution.

Khory, T. G. (1996). Personality Characteristics, Behavior and Relationship to Learning. Beirut: University Foundation for Studies, Publishing and Distribution.

Mohammad, M. F. (2007). Emotional Intelligence and General Intelligence. Psychological Studies, 17, 481-511.

Rashed, R. M., \& Al-Husaini, A. M. (2012). Effectiveness of an Inspirational Program Based on Emotional Intelligence to Alleviate Future Anxiety among Special Education Teachers. Social \& Educational Studies, 18, 139-170.

Shuwaikh, H. A. (2012). The Five Big Factors of Personality as Triggers for Healthy Behavior among University Students. Journal of Social Sciences, 40, 61-105.

Taha, F. A. Q., Qandeel, S. A., Mohammad, H. A. Q., \& Mostafa, K. (2009). Encyclopedia of Psychology and Psychanalysis. Qairo: Egyptian Anglo Bookstore. 